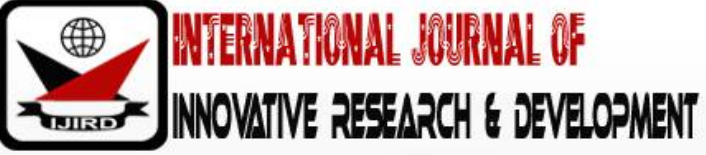

ISSN 2278 - 0211 (Online)

\section{Assessment Strategies to be Emphasised in Physics Teacher Education for Acquisition of Pedagogic Skills requisite for Effective Secondary School Instruction}

\author{
Stellah Mutiembu Mukekhe \\ Lecturer, Department of Science and Mathematics Education, Kibabii University, Kenya
}

\begin{abstract}
:
For effective classroom instruction, assessment of learning outcomes is of absolute priority, in light of this, teacher education in public universities ought to offer a variety of assessment strategies to be used in secondary school instruction. However, there are concerns that physics teachers lack skills necessary for effective assessment of their students' learning. This has been blamed for the poor performance of $38.27 \%$ recorded in the Kenya Certificate of Secondary Education (KCSE) physics examinations in the years 2007 to 2016. The aim of this study was to establish assessment strategies to be emphasised in physics teacher education for acquisition of pedagogic skills, and the target population was 420 physics student teachers, 277 heads of physics subjects and 130 physics teacher trainers. Data was collected using questionnaires and through analysis of documentary evidence. Findings reveal that assessment strategies to be emphasised in physics teacher education are questioning, assessment of project work, assessment of laboratory reports, portfolio analysis and use of information technology in assessment. The findings may be useful to public universities in Kenya to enhance the use of assessment strategies that should be emphasised for acquisition of pedagogic skills.
\end{abstract}

Keywords: - Assessment Strategies, Pedagogic skills, Public Universities, Students with learning disabilities

\section{Introduction}

Use of assessment strategies that support learning of physics is one of the key elements in teacher training where teachers are prepared on how to plan, implement, document and analyse investigations in instruction. Bullock, LaBella, Clingan, Ding and Thibado (2006) have argued that purposes, approaches and tools for assessment should be congruent with instruction, be continuous, be based on authentic tasks and focus on meaningful learning processes. Also the context of assessment should be guided by what students know, can understand and is appealing to the strengths of the students. Assessment should therefore be a collaborative process that involves students, should be multi-dimensional and uses a wide range of tools and strategies as it focuses on what students have learned and can do.

However, Stiggins and Conklin (1992) have observed that, as much as teachers are primarily responsible for evaluating instruction and student learning, with the common consensus that teachers use a variety of assessment techniques, teachers may be inadequately trained in certain areas of classroom assessment. This sentiment was also made by Zhicheng and Judith (2003).Moreover, Gibbs and Coffey (2004) observe that generally, majority of the teachers simply assess their students for promotion and very little of conceptual knowledge is verified and they further blame these on the training process that teachers underwent. While Oleson and Hora (2012) have argued that teachers often assess students in ways that they were taught by replicating models that were used during training some of which are ineffective.

In announcing the changes in policy on reforms in assessment in England, teachers were given greater responsibility for assessment in which information on performance of students was gathered routinely (William, 2004). This led to focus on improving the ability of the teachers to conduct the required assessment of the learners, where teacher education was tasked with equipping the trainees with the required knowledge and skills to facilitate meaningful and valid assessment with little bias. Ramsey, Nemeth and Haberkorn (2013) further reported that assessment strategies used by the teachers in England helped students take responsibility of their own learning.

Integration of assessment into daily instruction offers students frequent opportunities to gain feedback to modify their learning approaches and to monitor their progress. Continuous assessment equally provides on going opportunities for teachers to review and revise instruction, content and learning resources (Dufresne, 2004). To assess students' knowledge, skills and attitudes in physics, teachers require a variety of tools and approaches that ought to be focused on during the training of teachers (Taylor \& Dana, 2003). The approaches may include asking questions, observing students as they engage in a variety of learning activities and examining student work in progress. It is important that teachers also guide students in peer assessment and self-assessment activities (Huaying, 2012). The information that teachers and students gain from assessment activities informs follow up actions in the classroom. 
Similarly, Dufresne has argued, project work develops the thinking processes, inquiry skills, and scientific attitudes of students while McWilliam, Poronik, and Taylor (2008) have suggested that teachers should be equipped with the following assessment strategies for effective instruction; observation, interview, group assessment, students' self-assessment, student demonstrations, laboratory reports and use of in research. This guided the development of questionnaire items in the current study in order to establish which of the strategies should be emphasised in physics teacher education programmes for acquisition of pedagogic skills.

Some of the universities that have endeavoured to address the modalities of assessment during training of teachers include the Florida International University which has also taken wide initiatives to attract and retain students in physics-related careers (American Physical Society, 2013). In addition, the James Madison University has been exceptional for sustaining a strong teacher education effort through implementation of research based assessment during physics teacher training process. Since assessment skills of teachers is as a result of the training that the teachers underwent, it is necessary that universities that offer physics teacher education should endeavour to review assessment strategies in order to link training to realities in secondary school instruction.

In Kenya, reviews witnesses on the training programmes of physics teachers in public universities has largely focussed on the general appropriateness of the programmes, modes of delivery of content and on alignment of the programmes to the mission and vision statements of the universities. Moreover, the Teacher Education in Sub-Saharan Africa (TESSA) formative report of 2014 raised concerns on the missing guidelines on assessment strategies in physics teacher education programme as the reviews have not adequately addressed existing instructional needs especially on assessment of learning outcomes. Similarly, in the unveiling of a team to steer curriculum reform process at the Kenya Institute of Curriculum Development (KICD), the Ministry of Education (MoE, 2016) reiterated the urgent need for relevant and quality education at all levels. The MoE further called for improvements on the training programmes of teachers if learners' achievement in KCSE physics examinations was to improve. And to also enable teachers monitor and evaluate the proposed reformed curriculum effectively.

\subsection{Research Questions}

The study sought to answer the following research questions:

- What are the frequently used assessment strategies by teacher trainers in physics teacher education?

- What are the frequently used assessment strategies by student teachers in secondary school physics instruction?

- Which assessment strategies should be emphasised in physics teacher education for acquisition of pedagogic skills?

\section{Methods Employed in the Study}

\subsection{Research Design}

The design of the study was a descriptive survey because it reports and attempts to describe intents, behaviour and characteristics by individuals and groups. Apuke (2017) recommend the foregoing approach as it is useful when an accurate and extensive description of an educational practice is required and this made the design appropriate for this study.

\subsection{Area of Study}

The research was conducted in six (6) public universities in Kenya namely, the University of Nairobi (UoN), Moi University (MU), Kenyatta University (KU), Egerton University (EU), Maseno University (MSU) and Masinde Muliro University of Science and Technology (MMUST). Although there are seven public universities in Kenya that were established by 2007 that are the focus of the current study, Jomo Kenyatta University of Science and Technology does not offer physics teacher education and therefore only six of the universities were selected for the study. The universities that participated in the study have collectively graduated the greatest proportion of physics teachers for secondary schools, as approximately 3000 out of the 3250 physics teachers employed in secondary schools in the 10 years were certified by any one of the six public universities (Inter University Council of East Africa, 2014). Moreover, ineffective assessment strategies have been witnessed in secondary school physics and blamed on the training process of the teachers underwent at the universities.

\subsection{Study Population}

The study population comprised 420 physics student teachers who were undertaking teaching practice from 6 public universities in Kenya. Taylor and Dana (2003) have argued that students on field attachment are better placed to give an account of the training because they are able to interpret it in the context of the demands of the job environment. The study population also included 277 heads of physics subject in secondary schools where the student teachers were undertaking their teaching practice and 130 physics teacher trainers from public universities, specifically drawn from the departments of pedagogy and content. This enabled the researcher solicit the views of the experts needed in the current study as advanced by Sullivan (2013).

\subsection{Sample Size and Sampling Techniques}

Purposive sampling was used in the study where the total population of 351 physics teachers on teaching practice, 225 heads of physics subject in secondary schools where the student teachers were undertaking their teaching practice 
and 108 physics teacher trainers participated in the study. Ilker, Sulaiman \& Rukayya (2016) have noted that purposive sampling enables the entire population that meets the criteria of specific skills set or experience desired to be included in the study.

\subsection{Research Instruments}

The survey used Questionnaire for Physics Student Teachers, Questionnaire for Heads of Physics Subject, Questionnaire for Physics Teacher Trainers and Document Analysis Guide. The Questionnaire method was used as a primary source of gathering data where both qualitative and quantitative data were collected, while document analysis focused on documents that were deemed relevant in the current study.

\subsection{Validity of the Instruments}

To address face validity in this study, improvement on each of the items in the data collecting instruments was done by scrutinizing each item where clarity, readability and ambiguity were addressed. This ensured that each item met the intended performance. Content validity of the instruments was determined by piloting of the research instruments which formed the first phase of the study. Data collected from the pilot study was evaluated with reference to credibility, relevance and scope in answering the research questions and basing on the researcher's experience during piloting, where some respondents sought clarification on some of the items, adjustments were made on the items that improved the efficacy of the research instruments.

\subsection{Reliability of the Instruments}

The reliability of the questionnaires was established by computing a test-retest reliability coefficient. This was done after administering the instruments to the same respondents twice at an interval of two weeks (Hinton-Bayre, 2010). The respondents included 67 physics student teachers from one of the universities, 38 heads of physics subjects in secondary schools where the student teachers undertook their teaching practice and 22 physics teacher trainers from the university. The sample for piloting formed approximately $16 \%$ of the population which is above the $10 \%$ minimum advanced by Apuke (2017).Reliability of the instruments was also considered with reference to comprehensiveness of data, as in the case of the number of items in each of the data collection instruments. This is in line with assertions by Filkins and Ferrari (2004) who recommend more questions on an element of study to guarantee reliable of the instrument. Pearson product moment correlation $(\mathrm{r})$ was used to determine the correlation coefficients where the instruments were judged as reliable for use as the $\mathrm{r}$ values for all the instruments were above the recommended threshold of 0.70 (Johnson, 2016).

\section{Results}

\begin{tabular}{|c|c|c|c|}
\hline \multirow{2}{*}{ No. } & Assessment Strategies & \multicolumn{2}{|c|}{ Overall Mean Score out of 5 } \\
\cline { 2 - 4 } & Assessment by observation & 3.31 & Teacher Trainers \\
\hline 1 & Questioning & 4.62 & 2.01 \\
\hline 2 & End of topic tests & 4.01 & 3.52 \\
\hline 3 & Standard examinations & 4.25 & 3.33 \\
\hline 4 & Peer assessment & 2.32 & 1.92 \\
\hline 5 & Assessment of project work & 1.94 & 1.44 \\
\hline 6 & Group assessment & 4.24 & 2.97 \\
\hline 7 & Students' self-assessment & 2.48 & 2.41 \\
\hline 8 & Assessment of laboratory reports & 1.85 & 1.66 \\
\hline 9 & Assessment of research reports & 2.62 & 1.98 \\
\hline 10 & Portfolio analysis & 1.38 & 1.39 \\
\hline 11 & Construction of assessment items & 2.90 & 4.62 \\
\hline 12 & examinations & 4.01 & 3.21 \\
\hline 13 & Adoption of assessment items from previous & 3.54 & 2.97 \\
\hline 14 & Use of a variety of assessment strategies & 3.02 & 2.93 \\
\hline 15 & Use of feedback from assessment to adjust methods & & 1.47 \\
\hline 16 & of teaching & 2.98 & 3.05 \\
\hline 17 & Use of feedback from assessment to adjust \\
& instructional resources & 1.53 & \\
\hline 18 & Use of assessment models that caters for students & & \\
\hline
\end{tabular}

Table 1: Use of Assessment Strategies by Physics Teacher Trainers and Physics

Student Teachers (Teacher Trainers, N=108; Student Teachers, N =351) 


\begin{tabular}{|c|c|c|c|}
\hline No. & Assessment Strategies & Frequency & Percent (\%) \\
\hline 1 & Questioning & 320 & 55.5 \\
\hline 2 & Project work & 318 & 55.2 \\
\hline 3 & Laboratory reports & 278 & 48.3 \\
\hline 4 & Portfolio analysis & 274 & 47.6 \\
\hline 5 & Use of IT in assessment of physics & 264 & 45.8 \\
\hline 6 & Group assessment & 253 & 43.9 \\
\hline 7 & End of topic tests & 231 & 40.1 \\
\hline 8 & Use of assessment models to that cater for students with & 214 & 37.2 \\
& learning disabilities & & 36.1 \\
\hline 9 & Peer assessment & 208 & 36.1 \\
\hline 10 & Standard examinations & 208 & 22.6 \\
\hline 11 & Student self-assessment & 130 & \\
\hline
\end{tabular}

Table 2: Assessment Strategies to Be Emphasised in Physics Teacher Education for Acquisition of Pedagogic Skills (Physics

Student Teachers, $\mathrm{N}=351$; Physics Heads of Subjects, $\mathrm{N}=225$ )

Qualitative data was also scrutinised and the following remarks were noted:

Student teacher 228: "It is important that I am taught how marking of practical work Is done" Head of physics subject29: "There are many students who need special assistance. Some are slow learners while others are sick. Physics teacher should be sensitive while assessing them"

A critical analysis of documentary evidence was also conducted and it was noted that little was mentioned on assessment strategies in the Kenya Institute of Curriculum Development (KICD) physics teaching syllabus. Similarly, analysis of the Teachers Performance Appraisal and Development tool (TPAD) revealed that teachers are expected conduct effective assessment of their students in teaching and learning of physics. However, little was mentioned on the assessment strategies to be used by the teachers.

\section{Discussions}

The finding of the current study that questioning is frequently used both by physics teacher trainers and by student teachers in secondary school physics instruction is in agreement with assertions by Harlen (2010) that questioning is a frequent part of physics talk. While Black and Harrison (2004) identified that teacher questioning can be used to collect evidence about students' understanding of what they know, what they can do, what they do not know and what they partly know. Similarly, Chin (2014) identifies questioning as key to active and meaningful learning and that it facilitates scientific enquiry. Chin further supports Harlen's stance that questions should come from both the teacher and the students and physics teacher education should endeavour to equip student teachers with techniques of effective questioning.

Jones and Alcock (2014) have identified techniques for effective use of questioning that the physics student teacher should utilize to enhance classroom communication. This includes the need to allow reasonable waiting time in order to provide students with sufficient opportunity to think after the question before they are called upon to respond. Teachers should also be able to use a variety of approaches that cover open-ended questions, questions that require more than a right or wrong answer and also, teachers should be able to refer to Bloom's taxonomy when developing the questions in order to promote higher order thinking. Dixon and Haigh (2009) have further discussed that one way to practise skills on assessment is to invite students to participate and engage in the phases of formative assessment by allowing students to contribute questions, ideas and thoughts. Apart from questioning, classroom interaction allows the teacher to gather information about the students through observation, listening to informal discussions and through reviewing of written tasks on boards or in students' notebooks. Pollard, Triggs, Broadfoot, McNess and Osborne (2008) have observed that information gathered from students may be stored and used to plan future learning opportunities.

Emphasis on the use of standard tests and end of topic tests in physics teacher education and secondary school physics instruction revealed in the current research agree in part with findings of a longitudinal research that followed a cohort of students for eight years in England (Pollard et al., 2009), and it was established that assessment by teachers in physics classrooms was largely summative. Further, teachers were increasingly focused on performance outcomes rather than learning processes of students and those students also had adopted summative criteria in commenting on their own work. As Williams (2001) has noted, summative assessment promotes shallow and superficial learning rather than deep conceptual understanding. Williams further argues that test performance can become more highly valued than what is being learned and methods of assessment may only be restricted to what is necessary for passing tests. Moreover, the current study has revealed that the assessment items used by the teacher trainers and student teachers are largely adopted from previous examinations, and the assessment items are rarely constructed. These points to the need for physics teacher education to impart the necessary knowledge and skills needed for student teacher to construct assessment items too.

Similarly, Boggs (2009) compared the assessment practices of student teachers from Mississippi and Tennessee and established that $83.2 \%$ of teachers from Mississippi spent class time preparing students for standard tests as they were determinants for certification and placement, while $54.8 \%$ of teachers from Tennessee used class time to prepare for tests which are not solely used for certification. The situation in Mississippi is partly similar to that in Kenya on the extensive use of standard tests in both physics teacher education and in secondary school physics instruction. The use of 
standard tests tends to align physics instruction to the attainment of desired grades in examination at the expense of other assessment strategies that can build the students' skills, knowledge and attitude in physics.

William (2004) has also discussed that tests inhibit the development of formative assessment which is proven to raise achievement levels and reduce the gap between high and low achieving students. In addressing the need for curriculum innovation, Marcelo and Marina (2014) emphasised the need for teacher education to equip prospective teachers with effective assessment strategies that are congruent with instruction, that are continuous, collaborative and that use a wide range of tools and methods in the development of the subject matter. While Tofade, Elsner and Haines (2013) argues that best practices for assessment in physics are centred on employing questions to introduce students to central concepts and principles hence the need of student teachers to be equipped with questioning skills.

Moreover, it is established that students' self-assessment and peer assessment are rarely used by physics student teachers in secondary school physics instruction, findings that are similar to those of a study conducted by Sue and Michael (2014) in which a trial of peer assessment took place with second year students. In the study done by Sue and Michael, it was found that when averaged, students were accurate in their marking with just a slight tendency to over mark by 0.11 out of 17 . It was thus concluded that when guided, students can give valid marks in peer assessment. Similarly, in a study conducted by Marsh (2007), it was revealed that peer assessment enhances students' meta-cognition, helps students make judgement about their own learning and provides them with information for setting goals and self-monitoring. Findings of the current research therefore create the need to utilise students' self-assessment and peer assessment in both physics teacher education and in secondary school physics instruction.

In encouraging the use of alternative assessment to testing, Aina (2013) has urged that incompetency of physics teachers in the area of effective utilization of resources in assessment is to blame for low learning outcomes witnessed in physics. Aina further notes that there is insufficient awareness on the use of resources in evaluating different content areas in physics. Similarly, in a study that sought to assess the impact of project work in physics instruction as conducted by preservice teachers at Kaye Academic College in Israel, it was established that project work was able to promote meaningful learning, higher motivation and active involvement of students in learning during the entire course (Olzan 2016). Project work also improved student attitudes towards learning physics, reduced fear and increased student self-efficacy and enjoyment of learning. When used in assessment, project work was seen as minimizing the fear associated with written examinations besides increasing the contact of students with resource materials. Moreover, in contributing toward the need to use project work in assessment of physics, the Kenya Institute of Education (2005) noted that project work offers varied experience to learners and that its use enriches experimentation and enhances the creativity of students

Findings of the current research that project work is rarely used in both physics teacher education and secondary school physics instruction also agrees with the assertions that assessment policies and practices in Kenya are heavily norm referenced and summative (Wanzala, 2016). Moreover, it has been established in this study that project work should be emphasised in physics teacher education for acquisition of requisite pedagogic skills necessary for effective secondary school physics instruction. On modalities of assessing students' project work, Okeke and Okeye (2013)recommends for creation of rubrics that outline the criteria of various components of the students' work that should be assessed for a more accurate and useful feedback. The rubrics further provide clear expectations for a project and examine the products as well as the entire project building process. This is alongside explaining what constitutes excellence in the project work and ways of minimizing bias and subjectivity in its assessment. Physics student teachers should therefore have an understanding of the need to involve their students in planning and executing of project work, and also, on the development of rubrics and understanding of the entire process of assessment of project work.

In support of the need to use laboratory reports in physics assessment, the American Association of Physics Teachers (AAPT, 2016) has discussed that physics laboratories should be used for engagement in significant experiences with experimental processes that include designing investigations. Laboratory work should develop a broad array of basic skills and tools of experimental physics and data analysis and the success in achieving laboratory goals is demonstrated by communicating results. The AAPT further argued that students should develop expertise in clear and cogent reporting of experimental design, observations, analysis and conclusion in a variety of formats such as informal group discussions, oral presentations, use of laboratory papers and laboratory reports. Moreover, Zhicheng and Barry-Stock (2003) observed that assessment as a feedback mechanism should be entrenched at all levels of experimentation to enhance learning of knowledge, skills and processes in physics. When assessment of practical work is improved, learning of physics is also improved.

In physics instruction, portfolios include a collection of student work samples that are assumed to reflect meaningful understanding of the underlying concept (Wartawan, 2017). In using portfolios in assessment of physics, a wide variety of products that may include tests, homework, laboratory reports and classroom presentations can be considered. Meng (2016) has further observed that portfolios provide an alternative assessment procedure to traditional examinations which usually provide a limited view of the knowledge a student has achieved. The use of portfolio analysis enables students to address problems grounded in real life context as tasks given are typically complex and require students to synthesise and apply problem solving approaches.

In contributing to the debate on the importance of portfolio analysis in physics, Amin (2013) has argued that tasks used in assessment of portfolios should be open-ended and should require students to use and apply knowledge in ways that demonstrate their understanding of the concept. It was further recommended by Amin that teachers should design checklists that indicate the essential steps to guide students in their portfolio building process. From the foregoing, it is important that physics teacher education should consider incorporating techniques needed in building and using portfolios assessment of learners' achievement. 
The policy of the government on $100 \%$ transmission rate from primary to secondary schools in Kenya (MoE, 2016) has seen learners with varied abilities and needs admitted in physics classrooms. Therefore, for the teachers to be able to manage physics instruction effectively, and enable all learners acquire physics knowledge and skill, physics teacher training should equip the teacher with relevant assessment strategies that cater for students with learning disabilities in mainstream classrooms. Neerusha and Anilaa (2014) have identified the need to allow extra time particularly when an assignment involves significant demands and writing skills. Moreover, there is need to provide supplementary assignment such as recorded interviews or handmade models. From the findings of the current study, it is necessary that assessment of students with learning disabilities is practised more effectively in physics teacher education and in secondary school physics.

One of the successful assessment strategy for use with students with learning disabilities in physics classroom have been identified by the West Lothian Council Educational Psychology Service (2017) as applying of wait time before calling on a student to respond. This method allows students who process information slowly to understand what the teacher asked and to think of the response. Moreover, teachers should be able to use multisensory approach to assessment where more than one sense is used at a time as it assists students who are struggling readers or who have a challenge in writing. Similarly, physics teachers can model in problem solving by using graphic organizers, use of the Universal Design for Learning (UDL) and through assessment strategies that allow students to learn in a more flexible way. Assessment strategies in physics teacher education should therefore incorporate approaches that cater for students with learning disabilities so as to improve communication and learners achievement in secondary school physics.

Use of Information Technology (IT) and related platforms offer opportunities for stakeholders to contribute to the education of students and it is an effective way of conveying information between students, teachers and amongst students (Mishra \& Koehler 2007). Student can access assessment tasks and guidelines through the use of IT and communication to parents on academic achievement of the learners can easily be conveyed. And as Bryan (2017) has noted, IT can also offer opportunities for teachers to evaluate their lessons and improve on subsequent lessons because teachers can access opinions of experts that can be used to restructure their assessment models. Physics teacher education should therefore equip student teachers with the required knowledge and skills in the use of a variety of assessment strategies more so, in the integration of information technology in physics assessment.

\section{Conclusions}

The frequently used assessment strategies by teacher trainers in physics teacher education include questioning, group assessment, use of standard examinations and use of end of topic tests. In secondary school physics instruction, student teachers frequently use standard tests and questioning. Moreover, assessment strategies to be emphasised in physics teacher education for acquisition of pedagogic skills requisite for effective secondary school physics instruction include: questioning, use of project work as an assessment strategy, assessment of laboratory reports, portfolio analysis and the use of information technology in assessment of physics.

\section{Implications}

Public universities in Kenya to enhance the use of assessment strategies that should be emphasised in physics teacher education. This is to enable student teachers acquire pedagogic skills requisite for effective secondary school physics instruction.

\section{References}

i. Aina, J. K. (2013). Instructional Materials and Improvisation in Physics Class: Implications for Teaching and Learning. Journal of Research and Methods in Education. 2 (5): 38 - 42.

ii. American Association of Physics Teachers (2017). The 2017 Annual Report. Retrieved December 2, 2017 from

iii. $\quad$ https:/ / www.aapt.org/ aboutaapt/ upload/ 2017-Annual-Report.pdf

iv. American Physical Society (2013). The Physics Teacher. Retrieved August 10, 2014 from

v. scitation.aip.org/content/ aapt/journal/ajp.

vi. Amin, M. T. (2013). Portfolio-based Physics Learning Models to Improve Critical Thinking Skills. International Journal of Education and Research, 1(9): 12- 17.

vii. Apuke, O. D. (2017). Quantitative Research Methods: A Synopsis Approach. Retrieved September 4, 2017 from

viii. https:/ / www.researchgate.net/ publication/320346875_Quantitative_Research

ix. Black, C. \& Harrison, B. (2004). Assessment for Learning - Putting it into Practice. Berkshire: Open University Press.

x. Boggs, A. (2009). Alternative Assessment in the Secondary Physics Classroom. Research Paper submitted to graduate school of Ball state University, Indiana.

xi. Bullock, V. P., LaBella, T., Clingan, Z., Ding, G. \& Thibado, P. M. (2006). Enhancing the Student-Instructor Interaction Frequency. Journal of Physics Teaching, 3(40): 535 - 541.

xii. Chin, C. (2014). Teacher questioning in science classrooms: Approaches that stimulate productive thinking. Retrieved

xiii. May 16, 2016 from https:/ / onlinelibrary.wiley.com/ doi/ abs/ 10.1002/ tea.2017

xiv. Dufresne, R. J. (2004). Assessing-to-learn: Formative assessment in physics instruction. Retrieved January 20th, 2017 from http:/ / kolt.ku.edu.tr/ wp-content/ uploads/ sites/ 18/ 2016/ 06/ dufresne- 2004alf.pdf

xv. Dixon, H. \& Haigh, M. (2009). Changing Mathematics Teachers' Conceptions of Assessment and Feedback. Teacher

xvi. Development, 13(2): 173 - 186. 
xvii. Filkins, J. W. \& Ferrari, J. R. (2004). The DePau Values Project and the Devi: Assessing Students' Perceptions of a private

xviii. University's Core Mission and Values. Journal of collage and Character, 2(1): 1 - 39.

xix. Gibbs, G. \& Coffey, M. (2004). The Impact of Training and University Teachers on their Teaching Skills and their

xx. Approach to Learning of Students. London: Sage Publication.

xxi. Harlen, W. (2010). Purposes and Procedures for assessing science process skills. Assessment in Education Principles,

xxii. Policy and Practice, 6 (1): 129 - 144.

xxiii. Hinton-Bayre, A. (2010). Holding out for a reliability change from confusion to solution: a comment on maasses, "The standard error in the Jacobson and Truax Reliability change index. Journal for international Neuropsychol, 3(10): 894 - 898.

xxiv. Huaying, B. (2014). Development of Teacher Training in China. Paper presented at the National Forum of Teacher

xxv. Education, Cotonou. May 20th. Ilker, E., Suleiman, A. M. \& Rukayya, S. A. (2016). Comparison of Convenience Sampling and Purposive Sampling.

xxvi. American Journal of Theoretical and Applied Statistics, 5(1): 1 - 4.

xxvii. Inter University Council of East Africa (2014). Report on External Peer Review of the Bachelor of Education Programmes

xxviii. Offered at Maseno University. IUCEA Johnson, R. D. (2016). How does a qualitative researcher remain objective and unbiased. Retrieved November 4, 2016 from

xxix. https:/ / www.researchgate.net/ post/How_does_a qualitative_researcherremainobjectiveandunbiased

xxx. Jones, I. \& Alcock, L. (2014). Peer Assessment within Assessment Criteria. Studies in Higher Education, 39(10): $1774-1787$.

xxxi. Marsh, C. J. (2007). A critical analysis of the use of formative assessment in school. Educational Research and Policy Practice, 6(2): 25 - 29.

xxxii. Meng, K. L. (2016). The Use of Academic Portfolio in the Learning and Assessment of Physics Students from a Singapore

xxxiii. Private College. International Journal of Assessment Tools in Education. 3(2): 151 - 160.

xxxiv. Mcwilliam, E., Poronik, P. \& Taylor, P. (2008). Redesigning Science Pedagogy: Reversing the Flight from Science.

xxxv. Journal of Science Education and Technology, 1(7): 17- 26.

xxxvi. Ministry of Education (2016). National Education Sector Plan. Volume One: Basic Education ProgrammesRationale and

xxxvii. Approach. Retrieved June 2, 2017fromwww.education.go.ke/index.php/ downloads/ category/17-policydocuments?

xxxviii. Mishra, P. \& Koehler, M. (2007). Technological Pedagogical Content Knowledge (TPCK): Confronting the wicked problems of teaching with technology. In R. Carlsen, K. McFerrin, J. Price, R. Weber, \& D. Willis (Eds), Proceedings of Society Information Technology \& Teacher Education International Conference 2007. Pp 2214 - 2226.

xxxix. Chesapeake, VA: AACE.

xl. Neerusha, B. \& Anilla, A. (2014). Using Universal Design for Learning to Construct Inclusive Science Classrooms for

xli. Diverse Learners. Learning Landscapes, 7 (2):59 - 80.

xlii. Okeke, S. O. \& Okeye, N. E. (2013). Effective Resource Utilization. A better Approach to Teaching and Learning of

xliii. Physics. Physics journal of Interdisciplinary Studies, 2(6): 35 - 39.

xliv. Oleson, A. \& Hora, M. T. (2012). Teaching the way they were taught? Revisiting the sources of teaching knowledge and the role of prio experience in shaping faculty teaching practices. Retrieved August 10, 2014, from http:// www.wcer.wibc.edu/ publications/ workingPapers/ papers.php

xlv. Olzan, O. (2016). A project-based learning approach to teaching physics for pre- service teacher education. Retrieved

xlvi. April 22, 2017 fromhttp:/ / dx. do/ org/ 10.1080/ 2331186X.2016.1200833

xlvii. Pollard, A., Triggs, P., Broadfoot, P., McNess, E. \&Osborn, M. (2008). What Pupils say: Changing Policy and Practice in Primary Education. Journal of Educational Change, 4(1): 81 - 87.

xlviii. Ramsey, G. P., Nemeth, M. M. \& Haberkon, D. (2013). Physics Pedagogy and Assessment in Secondary Schools in th

xlix. US. Retrieved March 2, 2016 from https:/ / arxiv.org/ pdf/ 1305.4576

l. Stiggins, R. J \& Conklin, N. F. (1992). In Teachers Hands, Investigating the Practices of Classroom Assessment. Albany: State University of New York Press.

li. Sue, B. \& Michael, P. (2014). Peer assessment in physics. Retrieved January 27th, 2017 from https:/ / www2.warwick.ac.uk/ fac/ cross facliatl/ funding/ fundedprojects/ fellowships/ bell

final report supplemental.pdf

lii. Sullivan, G. \&Anthony, A. (2013). Analyzing and Interpreting Data from Likert - Type Scales. Journal of Graduate

liii. Medical Education. 5(4): 541 - 542.

liv. Taylor, J. A. \& Dana, T. M. (2003). Improving physics teacher preparation. Retrieve August 10, 2014, from

lv. phy.ilstu.edu/jpteo/ issues/jpteo1(4)mar03.pdt.

lvi. Tofade, T., Elsner, J. \& Haines, S. (2013). Best Practice Strategies for Effective use of Question as a Teaching Tool.

lvii. Americal Journal of pharmaceutical Education, 77(7): 155 - 161.

lviii. Wanzala, O. (2016 April 7th). Education Cabinet Secretary Matiangi set to unveil Team to steer Curriculum Reforms. 
lix. Daily Nation, pp 27. Nairobi: Nation Media Group.

lx. West Lothian Council Educational Psychology Service (2017). Effective Questionning. Retrieved August 3, 2018 from https:/ / www.westlothian.gov.uk/ media/ 268/ Questioning/ pdf/ Questioning.pdf

lxi. William, D. (2004). Assessment and the regulation of learning. Paper presented at invited symposium on what does it mean for classroom assessment to be valid? Reliable?. The annual meeting of the national council of measurement in education, San Diego, CA.

lxii. Zhicheny, Z. \& Judith, A. (2003). Classroom Assessment Practices and Teachers` Self Perceived Assessment Skills.

lxiii. Journal of Applied Measurement in Education, 16(4): 323-342. 